\title{
Investigation and Quantification of Water Track Networks in Boreal Regions of Alaska
}

\author{
Mendbayar, Uyanga, Misra, Debasmita, Gupta, Tushar and Ghosh, Tathagata \\ Department of Mining and Geological Engineering, University of Alaska Fairbanks, Fairbanks, AK, United \\ States \\ Email: umendbayar@alaska.edu; dmisra@alaska.edu
}

\begin{abstract}
Water tracks are the dominant drainage pathways that route water through the soil over permafrost in polar environments. Despite their important role in polar ecosystems, water tracks remain relatively unexplored, and the existing studies have been largely confined to tundra areas devoid of vegetation. This study aims to initiate the investigation of water tracks in thickly vegetated subarctic borealis, with objectives to: 1) characterize different types of water tracks in the subarctic; 2) develop methods for mapping water track distribution in boreal areas; 3) perform preliminary analysis of the geotechnical impacts of water tracks on engineered infrastructure. Two highly-varying water tracks were characterized, and led to different but quite promising insights. Several techniques to map water tracks in the subarctic were attempted. Preliminary analysis of geophysical data correlation was performed to determine geophysical signature of water tracks and to assess their geotechnical implications.
\end{abstract}

Keywords: Water tracks, drainage network, groundwater, hydraulic properties, remote sensing, infrastructure, Alaska, boreal region, subarctic, subsidence, sinkhole, climate change, impacts of climate change.

\section{Introduction}

In general, when there is a constraining subsurface boundary such as permafrost, clay, or bedrock, surface runoff forms rudimentary channel networks, known as "water tracks," through the soil [1]. Rowland et al. [2] stated that "Water tracks are linear and curvilinear features where enhanced soil moisture allows water to be preferentially and efficiently routed from hill slopes." Due to the extensive presence of continuous and discontinuous permafrost in polar environments, water tracks form the dominant drainage pathways, thus impose significant control on arctic and subarctic hydrology [1], [2], [3].

Despite being the major drainage networks in the polar regions, much of the behavior, characteristics, and impacts of water tracks remain relatively unexplored [3]. Existing literature on water tracks is limited, and is largely confined to ecological and hydrological studies in tundra areas devoid of vegetation and development. Nonetheless, water tracks are not only present in arctic tundra, but they also exist in subarctic borealis, intercepted by the predominant infrastructures in the subarctic. There has yet to be enough interest and funding invested in the investigation of interactions of water tracks with existing infrastructure and new construction.

Because water tracks in polar environments are primarily inhibited by permafrost, degrading permafrost has significant implications to how water tracks will be impacted by the global climate change. Hinzman et al. [4] speculated that the degrading permafrost will increase the subsurface water reservoir. Increased subsurface reservoir will further develop the water tracks into mature channels leading to hillslope erosions, larger amount of sediment transportation, and more unpredictable consequences. Kokelj et al. [5] observed that active layer detachment slides commonly occur in finegrained soils with low hydraulic conductivity on slopes underlain by ice-rich permafrost and areas of surface water convergence such as water tracks. Erin Trochim [6] suspects that additional water movement of water tracks could be thawing unstable ice-rich permafrost and creating thermokarst lakes (thaw lakes) during snowmelt runoff season when the water tracks have higher fluxes. All of these 
observed, predicted, and unpredicted implications inflict substantial threats and consequences to the arctic and subarctic landscapes, hydrology, ecology, and can potentially lead to serious geohazards that could threaten human safety and cause a tremendous economic loss by creating unstable slopes and damaging the current infrastructure.

First steps in investigating the interaction between water tracks and infrastructure are to: a) gain a better understanding of the basic characteristics and properties of water tracks; and b) to be able to delineate the distribution of water tracks. Water tracks are more prominent and easier to map in the Arctic tundra than in the subarctic borealis due to the difference in the density and types of vegetation. Nevertheless, some water tracks in boreal regions can be identified from Google Earth virtual map as patches of different vegetation health and growth, resulting from differential moisture availability.

This study focuses on water tracks in subarctic borealis and on the geotechnical implications of water tracks when intercepted with infrastructures.

\section{$2 \quad$ Research Goals and Objectives}

The primary objective of this study is to initiate the development of methods for mapping water tracks in subarctic boreal environments. However, it requires more comprehensive knowledge of behavior, characteristics, and variations of water tracks in boreal areas in order to design a methodology to map various types of water tracks that exist in the subarctic. With an objective to gain more insights into water tracks in the subarctic, two contrasting water tracks in Fairbanks area were characterized. The ancillary objective of the study is to conduct a preliminary analysis of the geotechnical impact of the water track drainage networks on engineered infrastructures.

The longer term research goals are to gain a systematic understanding of water track and infrastructure interactions, and to ultimately design engineering solutions to avoid water track related issues.

\section{Study Area}

In order to gain a better understanding of water tracks in boreal regions and determine better reflection signatures for mapping, two study areas were chosen in Fairbanks, Alaska. The study areas contain different types of engineered structures (i.e., road and residential house), yet a great amount of damage is present at each site, possibly due to the prominent water tracks intercepting the structures.

Characterization of two greatly varying water tracks were performed at the study areas. Further descriptions of each site and characterized track are presented in the following subsections.

\subsection{Study Area 1: Goldstream Road}

The main area of interest (AOI) for this study is Goldstream Road, north of city of Fairbanks, Alaska (see Figure 1). The road is approximately 10.4-mile, stretching east-to-west.

Goldstream Road experiences high amounts of damage resulting in a high maintenance cost. To investigate the road damages, the Alaska Department of Transportation (ADOT\&PF) in conjunction with the U.S. Army Cold Region Research and Engineering Laboratory (CRREL) conducted a geophysical study in 2012. The geophysical study encompassed a seven-mile resistivity survey (i.e., Capacitive-Coupled Resistivity-Electrical Resistivity Tomography or CCR-ERT) and a two-mile Ground Penetrating Radar (GPR) survey. A sample visualization of the geophysical data is presented in Figure 2 .

One of the prominent water tracks (in Figure 3) bisecting the Goldstream Road around Mile 7 (see Figure 4 for location of the track on the road) was characterized. The track seems to have been there for a long time; a small depression is apparent along the track due to the removal of fine material by the water flow in the track. A culvert (Figure 3) was put at the location where the water track is crosscut by the road. 


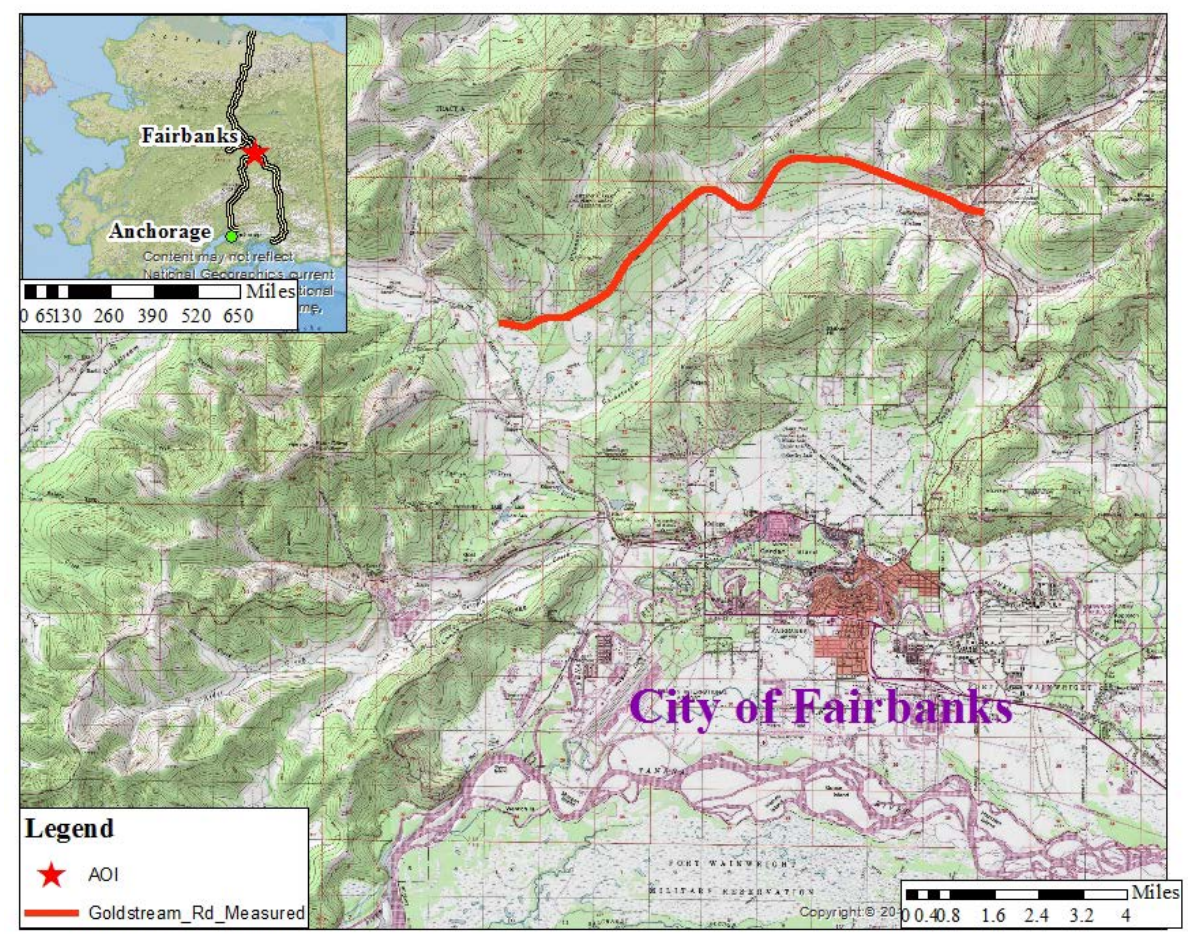

Figure 1. The location of the Goldstream Road (AOI). The inset map shows the location of AOI with respect to the State of Alaska.

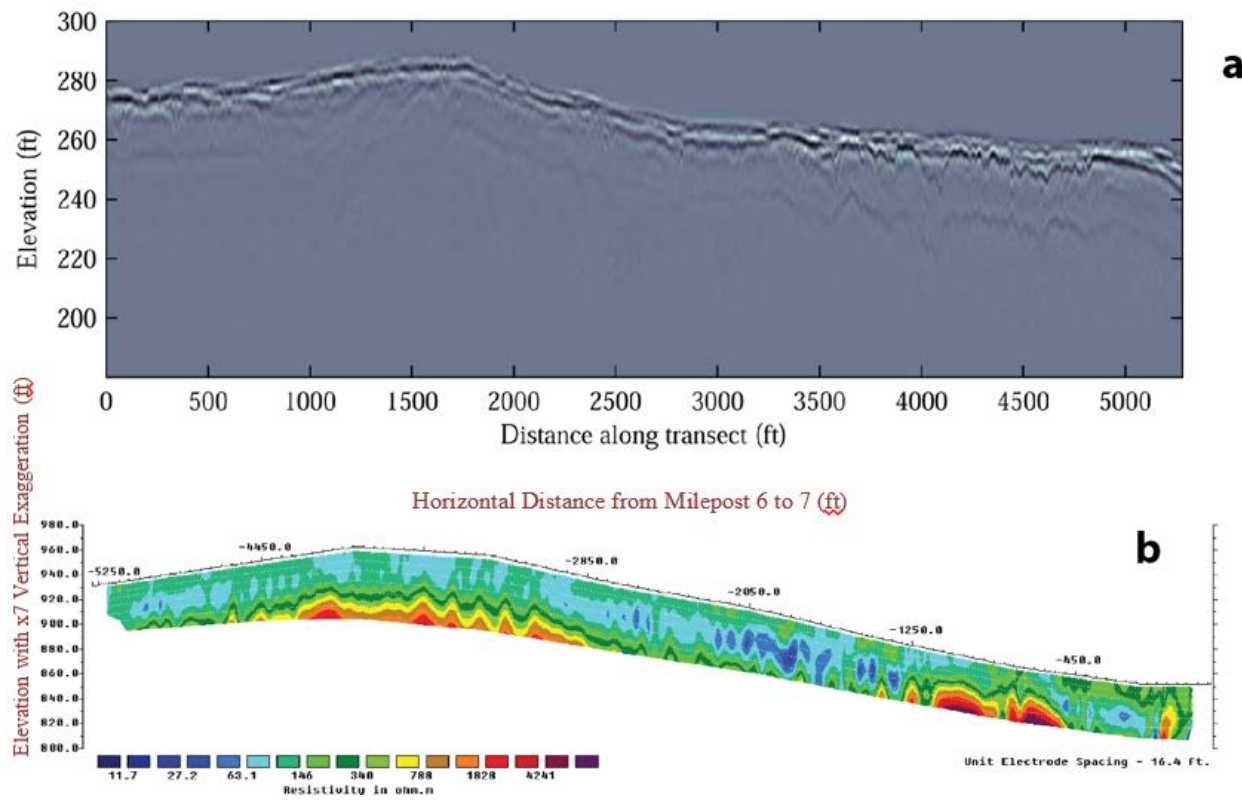

Figure 2. Goldstream Road geophysical results, Milepost 6-7.a) Topographically corrected GPR survey collected March 2011 b) CCR-ERT transect collected spring 2012 (courtesy of CRREL) on Goldstream Road mile 6 to 7 [7]. 

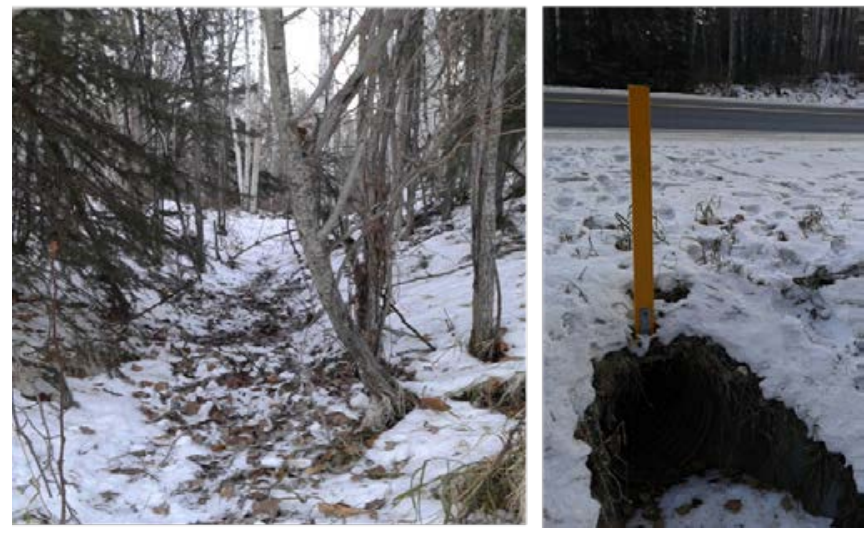

Figure 3. Prominent water track intercepting with the Goldstream Road. Water flow in the track has eroded the finer sediments over time so that the track resembles a rill.

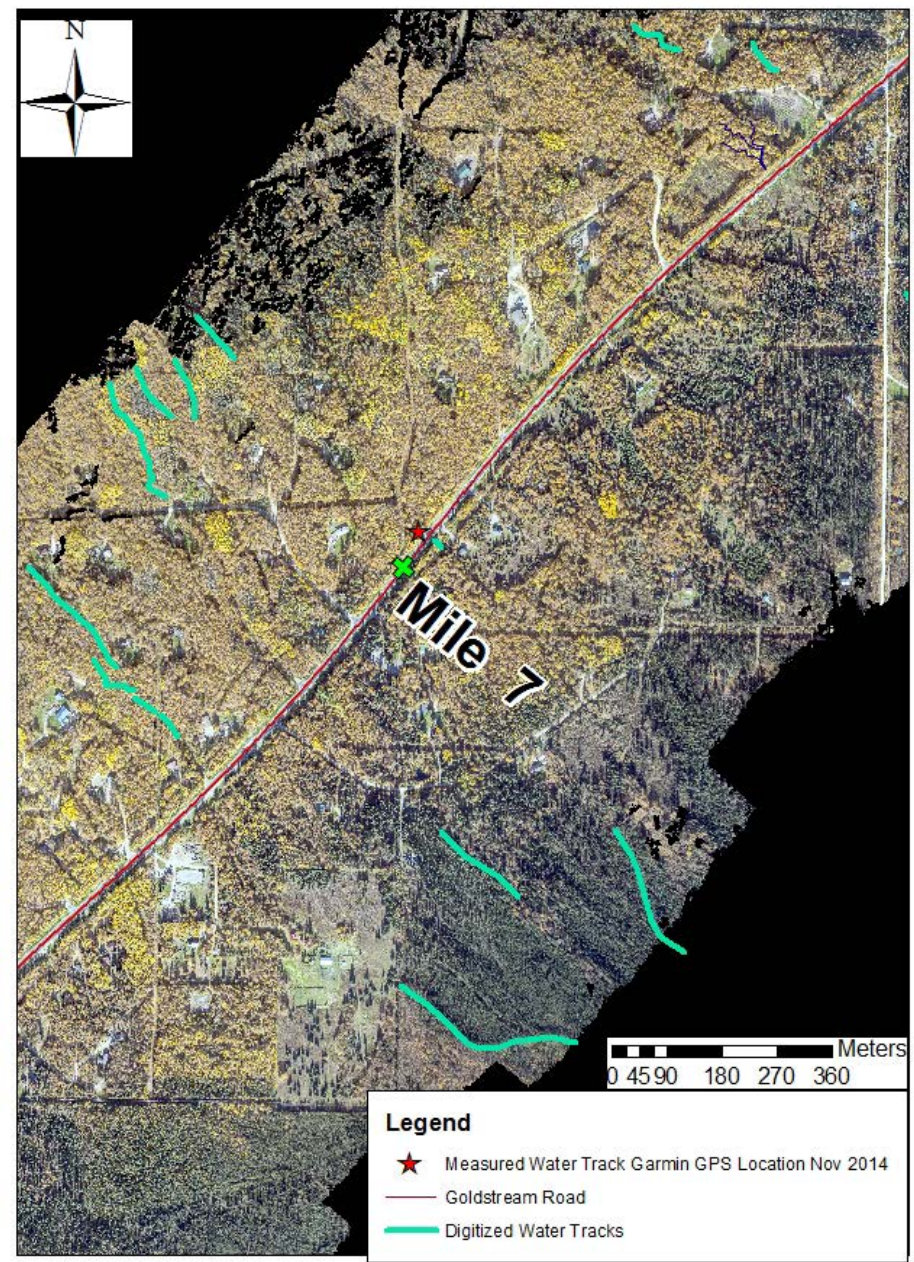

Figure 4. The location of the measured track in Figure 3 is marked with the red star. 


\subsection{Study Area 2: Martin's Property}

The second study area is located in a residential area, at the property of Bob and Mary Martin on Fabian Drive, northeast of Fairbanks, Alaska (Figure 5). A prominent water track (Figure 6) visible in summer of 2014 was characterized in November 2014.

Martin's property has been experiencing a significant amount of damage, which includes pervasive linear and curvilinear subsidence, (see Figure 7) in the recent years. The characterized track was prominently visible by its denser vegetation than the surrounding. It was located across the slope in front of Martin's house (Figure 6) in 2014 summer, but was no longer visible in 2015 summer. This track and its vicinity showed no sign of subsidence.

After the melting season of 2015, the damage at Martin's property was even greater than the preceding year: the property had subsided further with more linear and curvilinear depression features and a sinkhole had formed on their septic tank. It was observed that through-the-soil runoff flow in the water tracks has eroded the soil in the subsurface, creating cavities in ground which lead to potential for karst/sinkhole hazards.

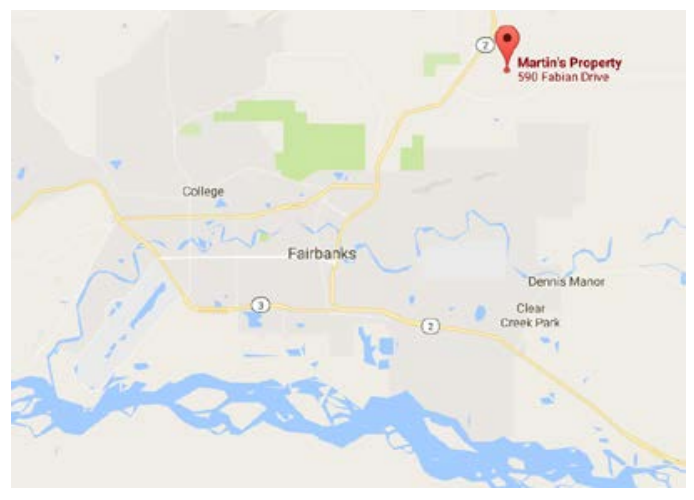

Figure 5. The location of Martin's property with respect to the City of Fairbanks

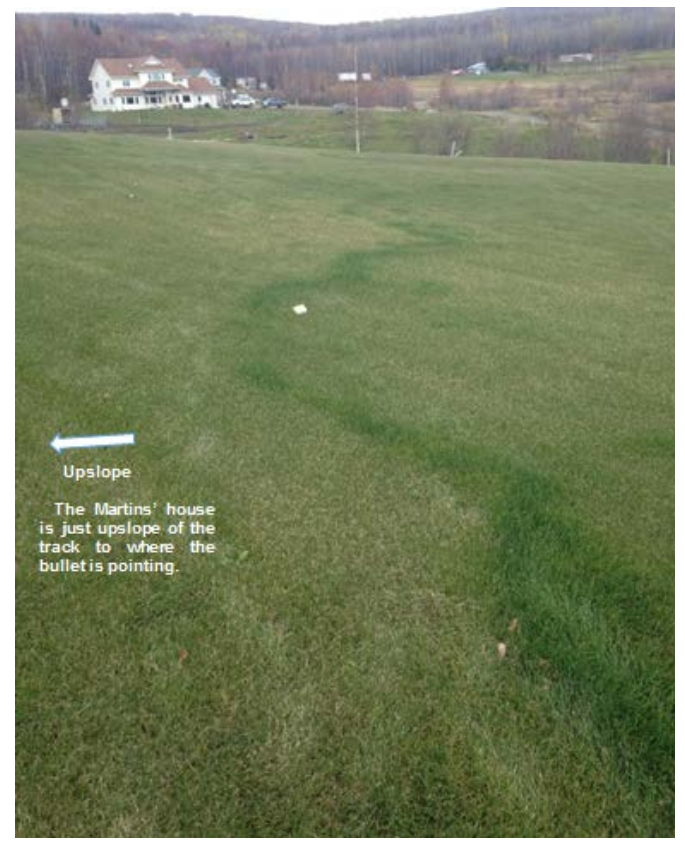

Figure 6. The location of Martin's property with respect to the City of Fairbanks 


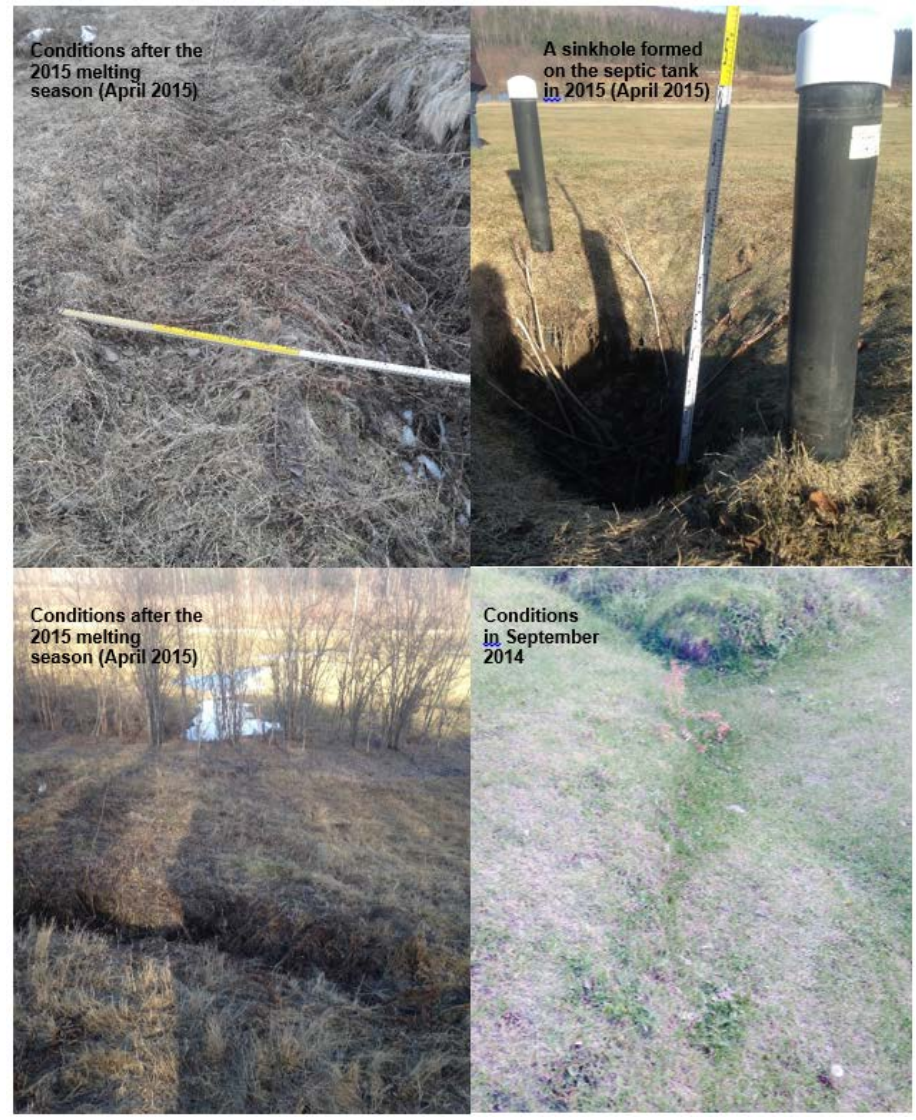

Figure 7. Subsidence and topographic changes observed at Bob and Mary Martin's property.

\section{Methodology}

The study encompassed characterizations of two contrasting subarctic water tracks, experiments with various remote sensing techniques for mapping water tracks in boreal regions, and a preliminary correlation analysis with geophysical data of the Goldstream Road. Methodologies used for each of these components are described below.

\subsection{Water Track Characterization at Goldstream Road}

At the water track on Goldstream Road, data was collected pre-winter (12/16/2014) and post-winter $(03 / 20 / 2015)$ on a vertical (along the track) and a horizontal (across the track) transects to observe the changes between the physical properties of the two transects. Figure 8 shows the survey set-up at the field. The air temperatures on $12 / 16 / 2014$ and $03 / 20 / 2015$ were recorded as $-12{ }^{\circ} \mathrm{C}$ and $+9{ }^{\circ} \mathrm{C}$, respectively.

The hypothesis of this characterization is that the soil water saturation and temperature along the water track and its surrounding are significantly different. Statistical F-test was used to test our hypothesis using the data collected. The temperature data was collected using a handheld oven thermometer. The Hydrosense II moisture probe was used to obtain the unfrozen moisture content along transects. Additionally, intrinsic permeability data was procured to understand its variability along and across the water track. The permeability data was collected using a handheld Tiny Perm II permeameter. 


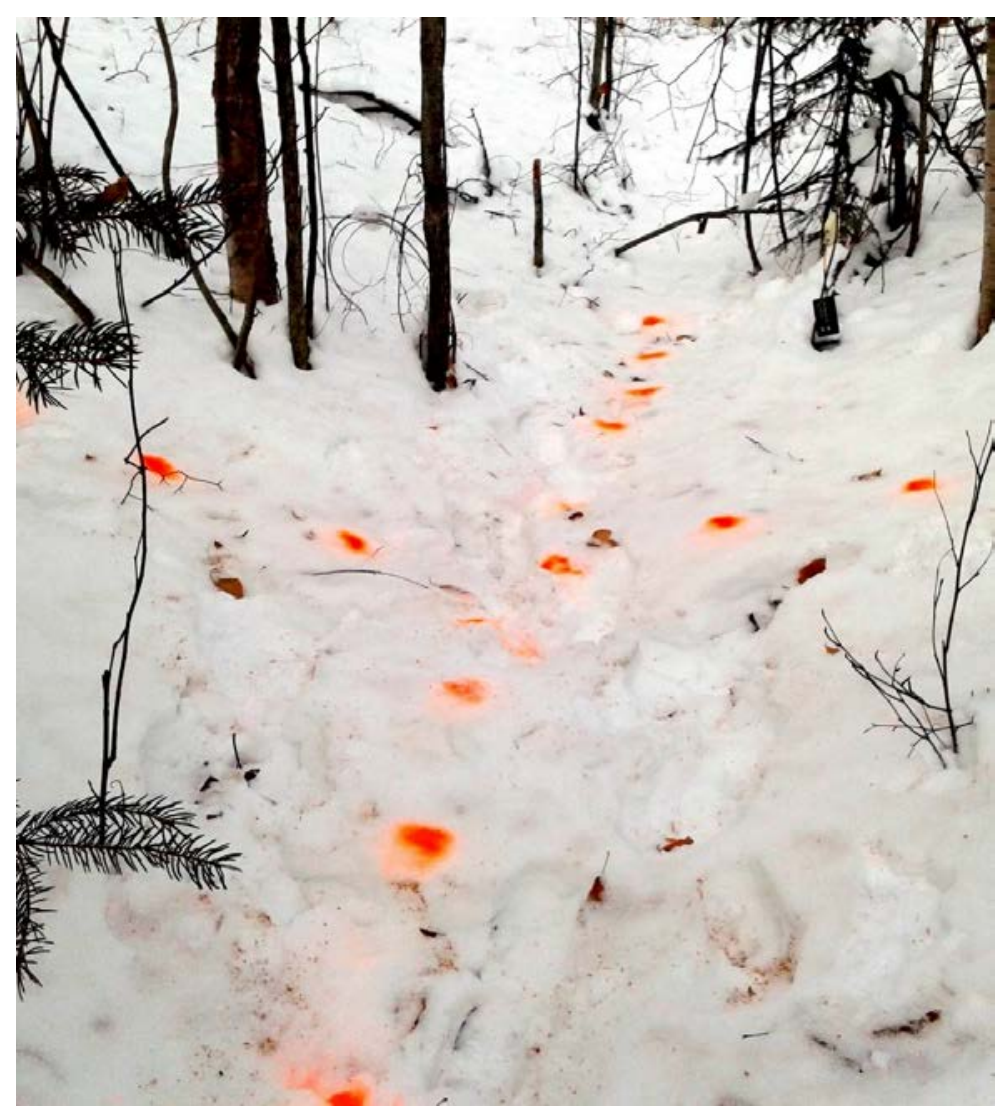

Figure 8. The water track sampling set-up near the Goldstream Road. N-S points on the downhill transect (referred as vertical transect) portray characteristics along the water track, and the E-W points on transect across the water track (referred as horizontal transect) characterize the water track surroundings.

\subsection{Water Track Characterization at Martin's Property}

At the second characterized water track at Martin's property, measurements were taken in November 2014, when the ground was covered with snow, and the air and soil temperatures were below freezing. The water track in front of Martins' house, hidden by snow cover, was located by observing photographs taken in early fall of 2014 (Figure 6). A nine-meter length transect—set up perpendicular to, and across the track (Figure 9)—was shoveled clear of snow. Along this survey line, measurements of soil temperature, unfrozen water content, and intrinsic permeability were taken at ten centimeter $(0.1 \mathrm{~m})$ intervals using the same equipment as the characterization at the Goldstream Road (i.e., oven thermometer for soil temperature; Hydrosense II sensors for unfrozen moisture content; and Tiny Perm II permeameter for intrinsic permeability).

Temperature and unfrozen water content measurements were taken approximately four centimeters beneath the surface. The frozen ground prohibited measurements from being taken deeper. Because of this, the Hydrosense II conductivity probes were not fully immersed in the ground and were exposed to air. This resulted in inaccurate measurements of unfrozen water content. Intrinsic permeability data was collected on top of frozen grass, and therefore is not perfectly representative of the soils beneath. As much snow and frozen grass as possible were removed in order to get a more characteristic reading.

For the analysis of the data collected, variability of intrinsic permeability along the nine-meter transect was analyzed using two methods: simple plot of intrinsic permeability across distance on transect and geostatistical semi-variogram fitting method. 


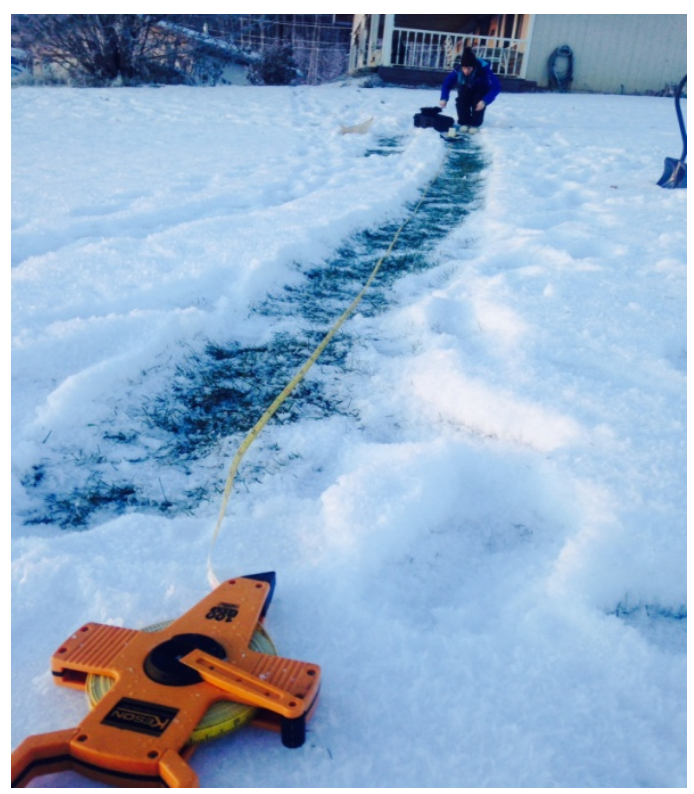

Figure 9. The transect across the water track at Martin's house being set up by Rebekah Tsigonis, former undergraduate student of Geological Engineering, University of Alaska Fairbanks (UAF) in fall 2014.

\subsection{Methods Used to Remotely Sense Water Tracks in Boreal Environments}

Since water tracks are relatively narrow features, extracting them requires high-spatial-resolution imagery. The availability of good-quality and high-spatial-resolution images in the study areas is quite scarce. Upon searching in the existing imagery, a 2010 SPOT 5 (2.5 m x $2.5 \mathrm{~m}$ ) multispectral image of the Goldstream Road was procured from the Geographic Information Network of Alaska (GINA).

To facilitate the need for high-quality and high-spatial-resolution imagery, an aerial orthophoto (resolution of $0.14 \mathrm{~m} \times 0.14 \mathrm{~m}$ ) and a Digital Elevation Model, DEM, (0.57 m x $0.57 \mathrm{~m}$ ) of Goldstream Road were acquired in September 2014 by Dr. Matt Nolan, a professor in College of Engineering and Mines at University of Alaska Fairbanks. Furthermore, handheld thermal infrared (IR) cameras-FLIR S40 and T620-were used at Martin's property to test whether the different thermal regime of water tracks can be captured by thermal IR cameras.

\subsection{Correlating Geophysical Data}

As a preliminary correlation analysis, the characterized water track on Goldstream Road was approximately located on the 2012 geophysical data with an objective to reveal the water track's geophysical signature and potential impacts to the road damage.

It should be noted that the geophysical data has poor geospatial information: only the approximate start and end locations of the resistivity survey along the old alignment of the Goldstream Road were given, and no spatial information of the GPR data has been provided. The location of the characterized water track in Figure 3 was obtained using a recreational-grade, Garmin, GPS. In the analysis, a fiftymeter zone was used to represent the water track position in order to offset the accuracy and precision errors of the spatial information of the resistivity data and the recreational-grade GPS unit.

\section{$5 \quad$ Results}

\subsection{Results from the Water Track Characterization at Goldstream Road}

Figure 11 shows the difference in saturation between the water track and its surrounding ground in pre- 
winter sampling. However, the limited difference is noted in post-winter sampling, suggesting that moisture redistribution was beginning to occur at that period of time. It may be noted from Figures 10 and 11 that in the post-winter data, significantly higher temperature and water saturation (e.g., the outlier in Figure 11) are measured at the bottom of the vertical transect - near the water track and road interception. This suggests that despite there being a culvert to route the water flow through the road fill, the runoff is possibly pooled in the subsurface at some point of the interception of water track and road fill. The F-test conducted on the difference of mean properties (temperature and water saturation) between the two transects show that these differences are statistically significant at $95 \%$ confidence level (Table 1).

Although Figure 12 data was not used in the testing of our hypothesis, it reveals that significant anomalies in intrinsic permeability along the track and its surroundings could be used effectively to identify water tracks. More researches are necessary to determine the use of intrinsic permeability as a parameter to characterize water tracks.

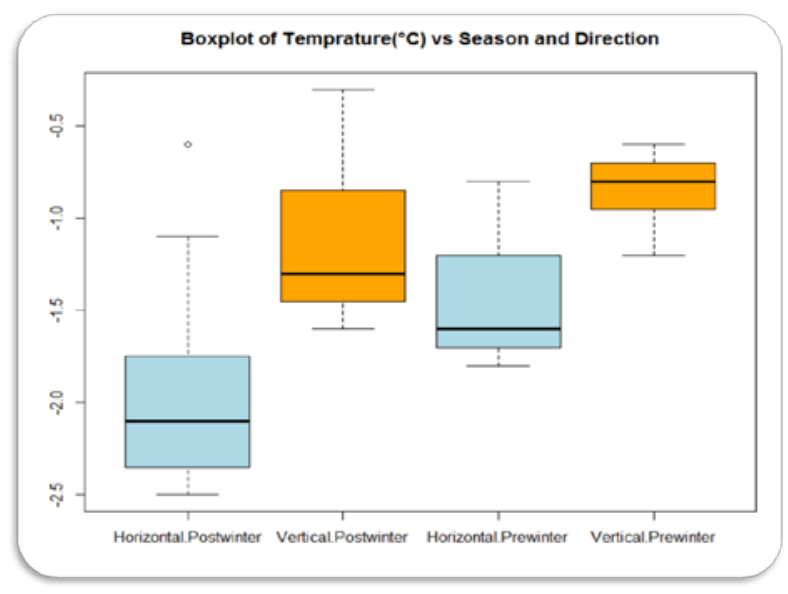

Figure 10. Boxplots of temperatures on- and off-track during pre- and post-winter seasons. Vertical transect (ontrack) represents along the water track areas, and horizontal transect (off-track) traverses across the water track, characterizing its surroundings.

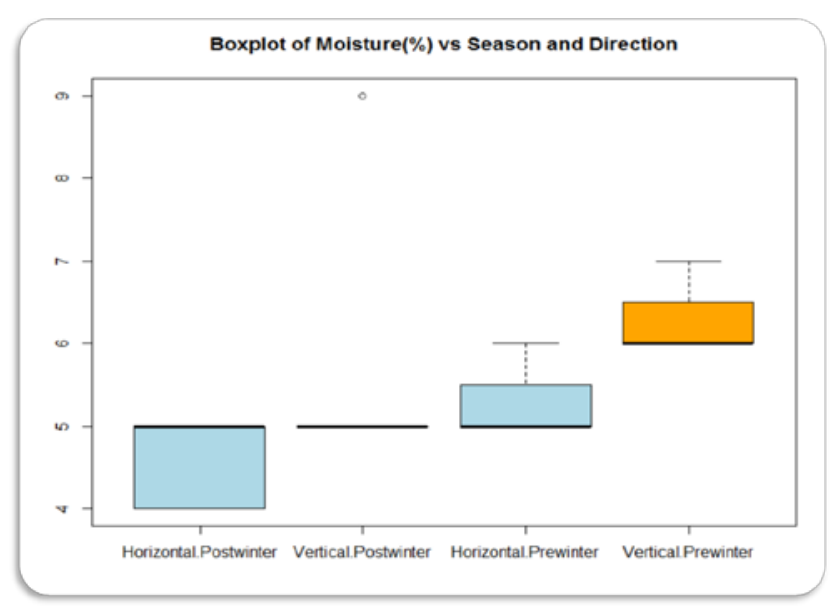

Figure 11. Boxplots of moisture content on- and off-track during pre- and post-winter seasons. 
Table 1. Boxplots of moisture content on- and off-track during pre- and post-winter seasons.

\begin{tabular}{|c|c|c|c|}
\hline & $\begin{array}{c}\text { Intrinsic } \\
\text { Permeability }(\mathrm{md})\end{array}$ & Moisture(\%) & $\operatorname{Temp}\left({ }^{\circ} \mathrm{C}\right)$ \\
\hline \multicolumn{4}{|c|}{ PostWinter } \\
\hline Horizontal Mean & 47.73 & 4.55 & -1.91 \\
\hline Vertical Mean & 53.47 & 5.36 & -1.15 \\
\hline Horizontal SD & 5.10 & 0.52 & 0.60 \\
\hline Vertical SD & 3.62 & 1.21 & 0.43 \\
\hline F-Statistc & NA & 4.26 & 11.63 \\
\hline P-Value & NA & 0.05 & 2.78E-03 \\
\hline \multicolumn{4}{|c|}{ Pre Winter } \\
\hline Horizontal Mean & 51.28 & 5.27 & -1.45 \\
\hline Vertical Mean & 51.62 & 6.27 & -0.82 \\
\hline Horizontal SD & 4.46 & 0.47 & 0.34 \\
\hline Vertical SD & 4.84 & 0.47 & 0.19 \\
\hline F-Statistc & NA & 25.21 & 11.63 \\
\hline P-Value & NA & $6.60 \mathrm{E}-05$ & $3.24 E-05$ \\
\hline
\end{tabular}

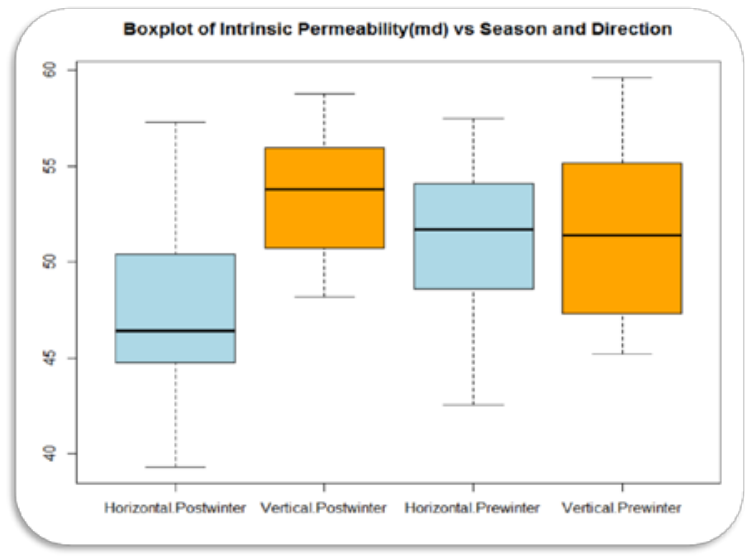

Figure 12. Boxplots of intrinsic permeability on- and off-track during pre- and post-winter seasons.

\subsection{Results from the Characterization at Martin's Property}

No apparent correlation among intrinsic permeability, moisture content, and surface temperature was observed from the second characterization field data obtained at Martin's property. However, it should be noted that the timing of the survey was not ideal for the equipment used, nor was the equipment apt for cold weather.

When the raw permeability data was plotted against the horizontal distance along the nine-meter transect (see Figure 13), it is observed that the permeability measurements of the first six meters of the transect line are significantly higher than those of the last three meters. The mean intrinsic permeability was calculated to be $137,935 \mathrm{mD}\left(1.36 \mathrm{E}-06 \mathrm{~cm}^{2}\right)$ from 0 to 6 meters and $6,471 \mathrm{mD}\left(6.39 \mathrm{E}-08 \mathrm{~cm}^{2}\right)$ from 6 to 9 meters. The mean permeability of the first section (0-6 $\mathrm{m}$ on the survey line) is over 21 times larger than that of the second section (6-9 $\mathrm{m}$ on survey line). This abrupt change in permeability implies the presence of zonal anisotropy, suggesting that there are possibly two geologic units along the survey line. The permeability profiles of each section (geologic unit) are presented in Figures 14 and 15.

Next, the variation in the intrinsic permeability is analyzed using geostatistical semi-variogram method. The variance of the raw data was calculated to be $6.41 \mathrm{E}-13 \mathrm{mD}^{2}$, which was used as the sill to 
fit semi-variogram models. The experimental semi-variogram was fit with two models: spherical and exponential. Of the two models, the spherical model seemed to be better representative of the continuity. The spherical model fits best with a nugget of $2.40 \mathrm{E}-13$ and a range of $3 \mathrm{~m}$. The small nugget value suggests that there is significant variability in the permeability at small distances along the transect line. The range of three meters suggests a change of zone within three meters, which agrees with what was observed from the raw data. A plot of the best-fit model along with the experimental semi-variogram and variance is shown in Figure 16.

Discussion with the property owners revealed that the zonal anisotropy was attributed to the zones of compacted foundation fill and natural soil. The first six-meter of highly permeable unit is the foundation fill material and the second unit (6 to $9 \mathrm{~m}$ on the transect line) with significantly less permeability is the natural soil. This suggests that the water track in Figure 6 was formed along the boundary between the fill and the natural soil - which also explains why the water track formed, not down, but across the slope - due to the contrasting permeability of the two units. This observation further suggests that water tracks may form along the boundary between two units with fairly different hydraulic properties.

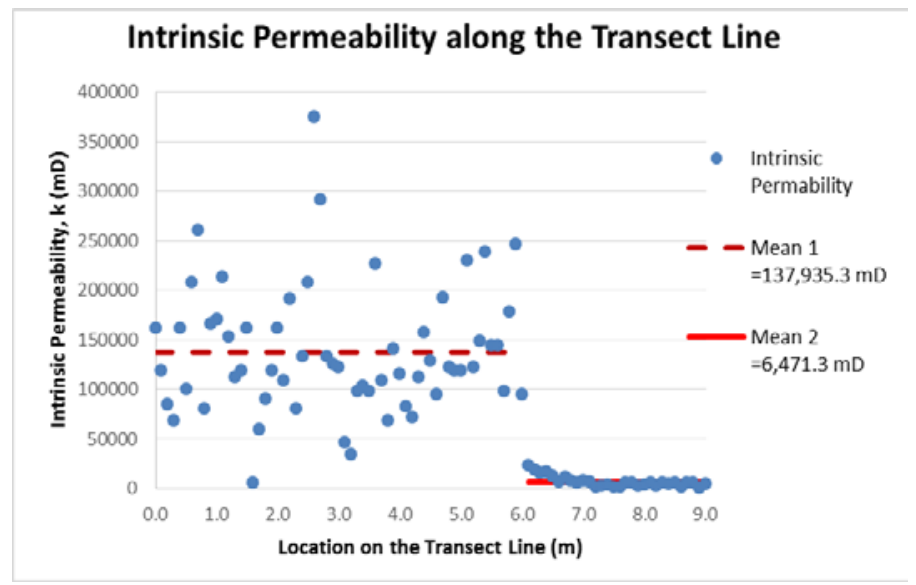

Figure 13. Obtained intrinsic permeability along the survey line, which increases from 0 to $9 \mathrm{~m}$ down the slope.

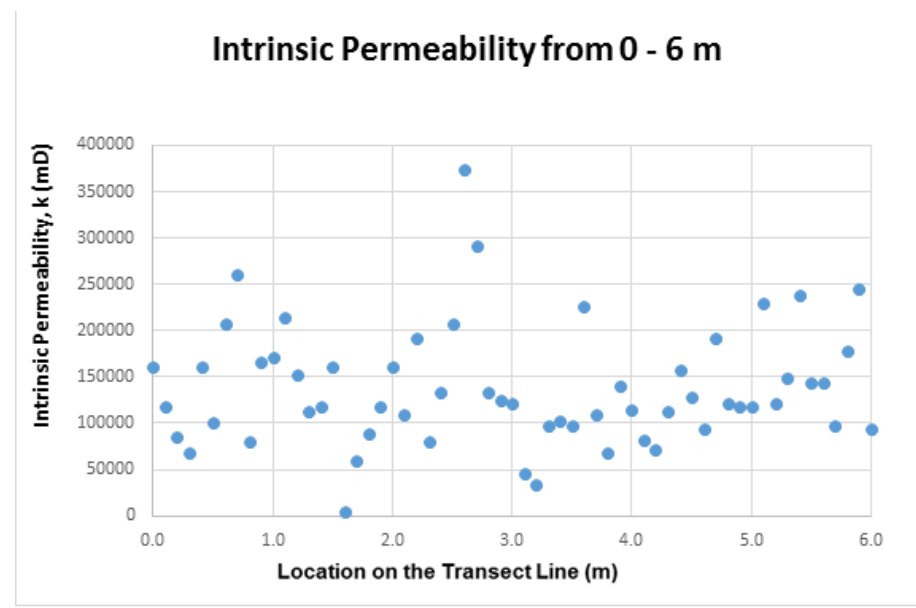

Figure 14. The intrinsic permeabiity of the first section of the survey line $(0 \mathrm{~m}$ to $6 \mathrm{~m})$ 


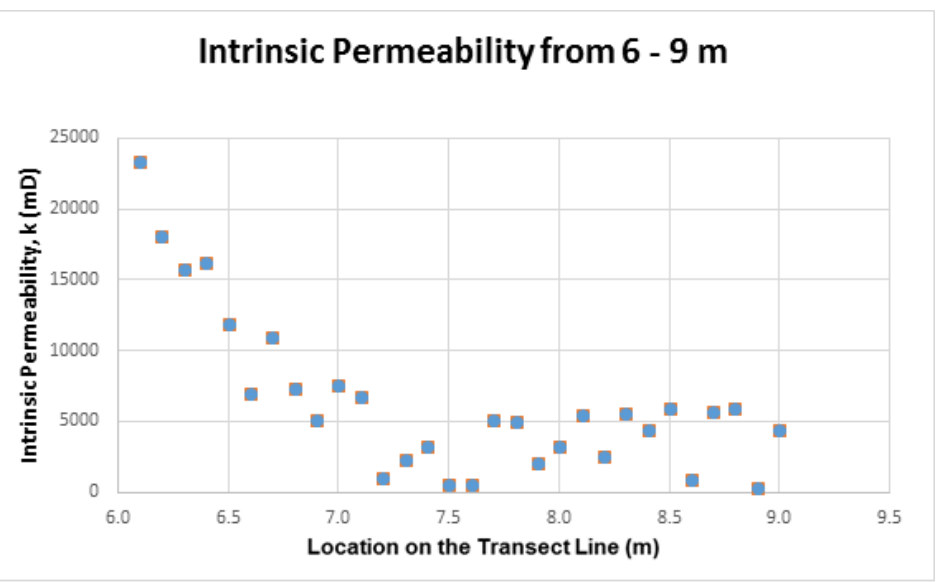

Figure 15. The intrinsic permeability of the last section of the survey line (6 $\mathrm{m}$ to $9 \mathrm{~m})$

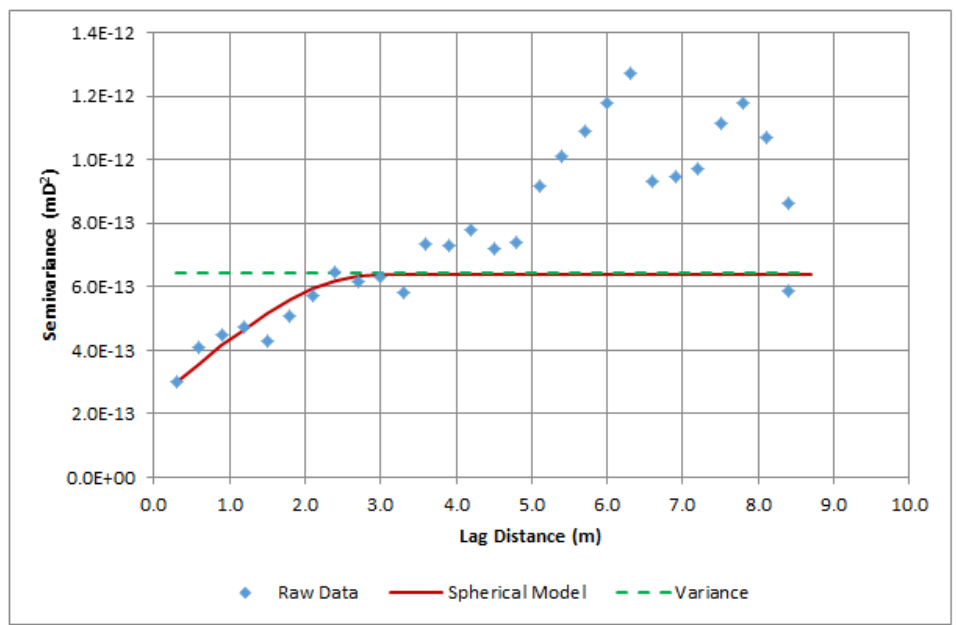

Figure 16. The plots of the experimental variogram and variance with the two models fit to the experimental variogram

\subsection{Results from the Efforts to Remotely Sense Water Tracks in Both Study Areas}

Normalized Difference Vegetation Index (NDVI) processing was performed on the 2010 SPOT 5 imagery to highlight healthy vegetation in the vicinity of Goldstream Road. As each pixel represents 2.5 by 2.5 meter area, it is barely possible to identify the different vegetation pattern along water tracks (which are even less than one-meter in width) versus the off-track areas.

In the high-spatial-resolution aerial orthophoto acquired by Dr. Nolan, there is a substantial amount of scattering and tree shades due to the tall canopy heights. This further led to the conclusion that thick vegetation in the boreal forests makes it infeasible to do image processing such as supervised and/or unsupervised classification on an image with bands of visible range and/or smaller wavelengths. However, with the high-spatial resolution of the aerial image, linear and curvilinear features such as roadways, trails, and water tracks are identified more easily. Because the characteristics, properties, and types of water tracks in boreal regions are not known, there is no other electromagnetic signature that can differentiate water tracks from trails and roadways using the visible bands of the aerial orthophoto. This further decreases the viability of automated processing of the orthophoto image. Therefore, the methodology was altered to digitize water tracks manually from the available images, based on, solely, 
their linear and curvilinear shape. A new personal geodatabase was created in ArcGIS to store the manually digitized water track shapefile. A predesigned structure was built into the digitized water track shapefile to include significant parameters such as vegetation on- and off-track, confidence level in whether it is a water track, and interception with infrastructure. When digitizing, all the available imageries (e.g., NDVI from SPOT 5 image, aerial orthophoto and DEM) were used along with Web Mapping Services (WMS) and Best Data Layers (BDL) from either AlaskaMapped or GINA. Sample digitized water tracks are shown in Figure 17.

Based on the vegetation pattern from the aerial orthophoto, it was observed that the Goldstream Road stretches through sections of lands with both presence and absence (seasonal-frost) of permafrost. Some parts of the road such as Mile 0-1 is heavily developed such that it is hard to tell if permafrost exists in those areas. Water track features were observed in both permafrost and seasonal-frost regions of the road (see Figure 17).

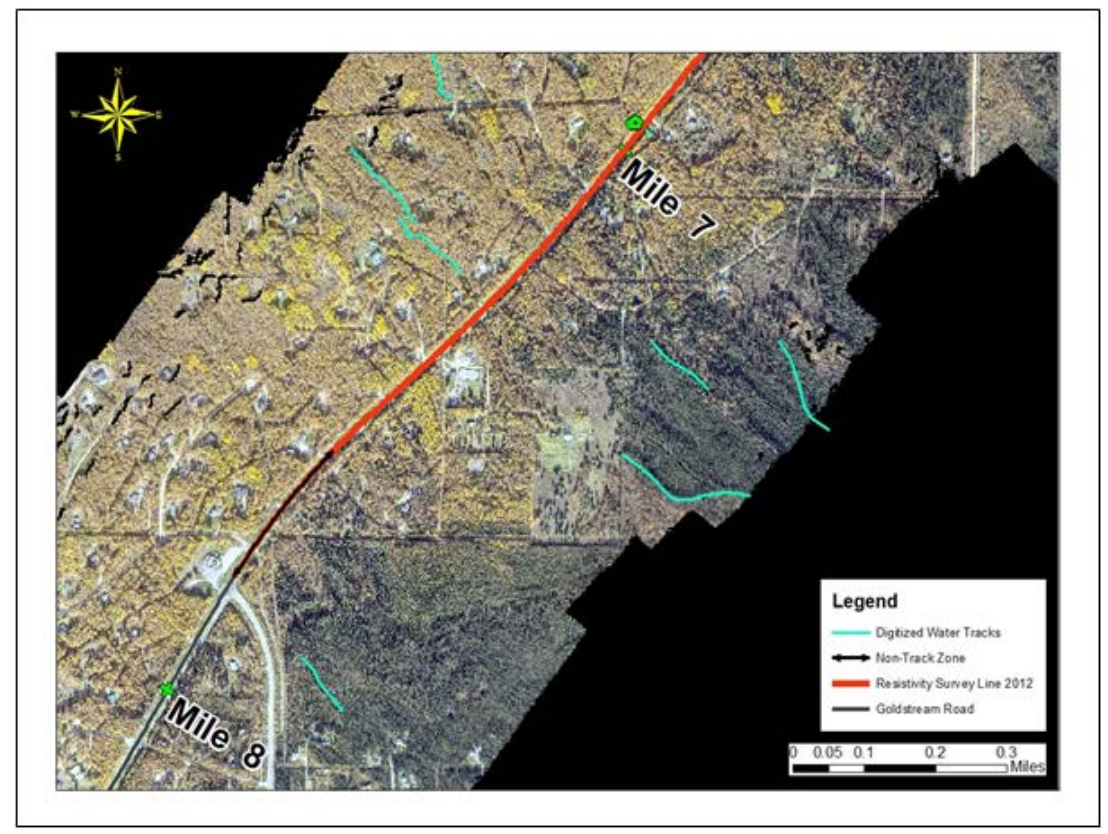

Figure 17. Sample digitized water tracks. On top (upslope) of the Goldstream Road, the yellow vegetation is deciduous and thus indicates absence of permafrost (seasonal-frost areas). Downslope of the road, the coniferous vegetation indicates presence of permafrost. As shown on the map, water tracks are identified in both permafrost and seasonal-frost areas.

With the handheld Thermal Infrared (IR) cameras, the different thermal regime along water track, due to its higher moisture content, was successfully detected by both cameras (i.e., FLIR S40 and T620) at two different times of the year. When the ambient temperature was relatively warm in late summer/early fall, the higher evapotranspiration from the water track was sensed as cooler than the surrounding (Figure 18). Whereas, when the air temperature was starting to drop in late fall/early winter, the warm moisture reserved in the water tracks from the summer radiated warmer thermal regime along the track compared to the surrounding areas (Figure 19). Both thermal images (Figure 18 and 19) have high spatial resolutions since they were acquired with cameras being handheld. Unmanned Aerial Vehicles (UAV) should be able to acquire similar high-spatial-resolution images covering larger areas.

Furthermore, it is recommended that more experiments and processing be done on images with wider wavelengths such as Short Wave Infrared (SWIR) and/or Thermal IR. However, availability of highspatial-resolution SWIR and/or Thermal IR is even more limited. An attempt was made to procure an IR image by an UAV, however the permit, relevant cost and time necessary were found to be infeasible for this project. 


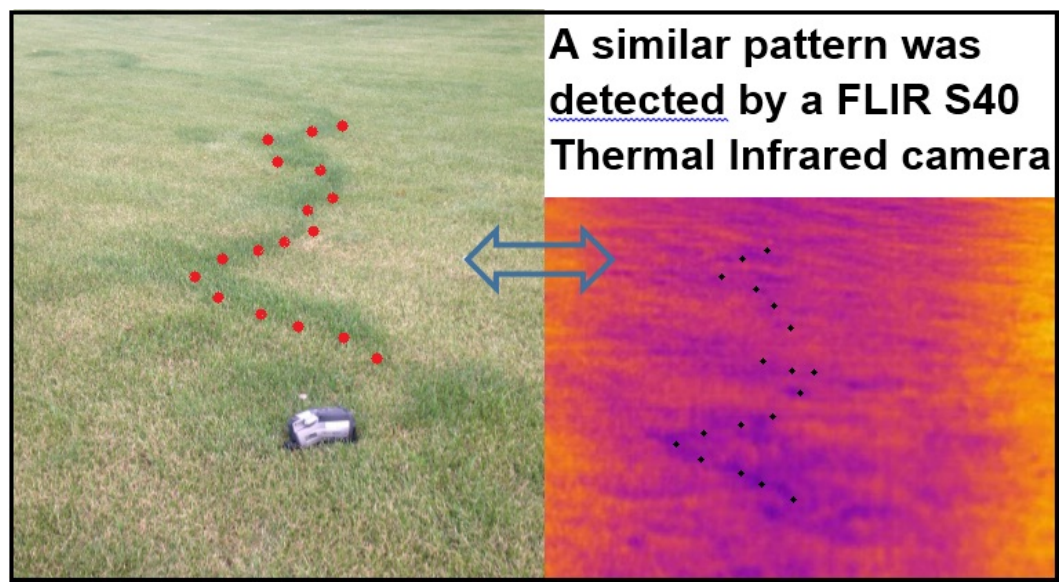

Figure 18. Water track captured by FLIR S40 camera when the temperature was relatively warm.
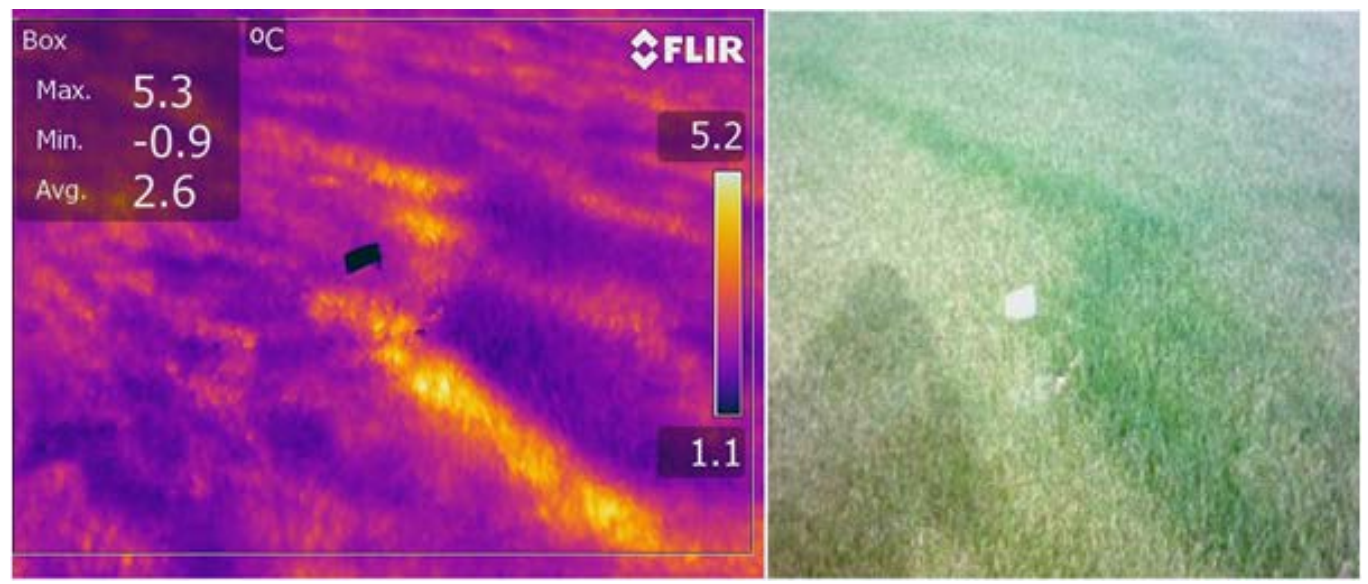

Figure 19. Water track captured by FLIR T620 camera when the temperature was dropping in late fall/early winter.

\subsection{Results from Correlation with Geophysical Data}

A 300-meter resistivity profile around the location of the characterized water track was extracted from the 2012 resistivity survey data of Goldstream Road. The fifty-meter approximate position (Figure 20) of the water track was then located on the 300-meter resistivity profile (Figure 21). The red dashed rectangle in Figure 21 represents the fifty-meter approximate position of the characterized water track. The lowest resistivity drop in the 300-meter profile was observed within the red rectangle. This suggests that water tracks might have lower resistivity than their surroundings, but more correlations using different analysis methods and with resistivity data from different times of the year are necessary to validate the conclusion from this correlation. 


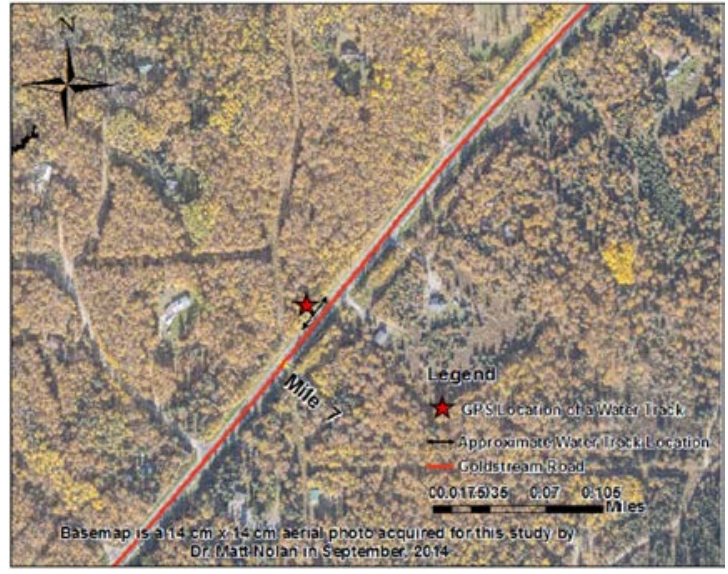

Figure 20. The location of the measured track along with the fifty-meter range of location.

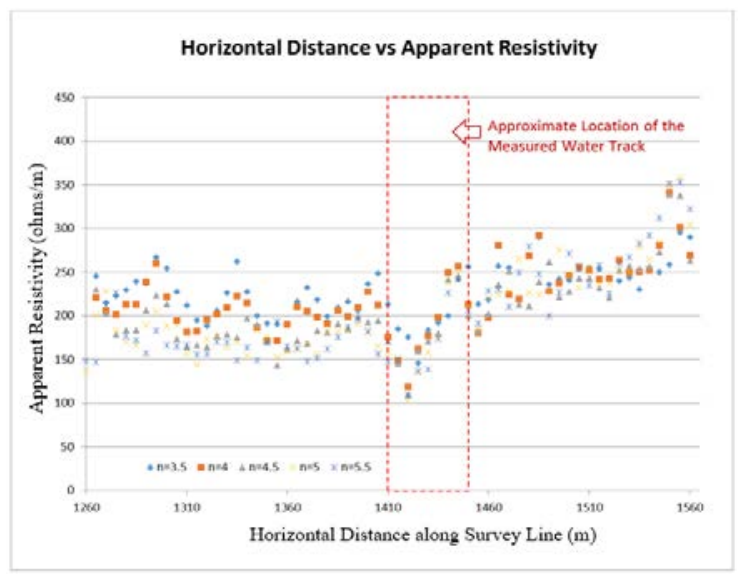

Figure 21. Resistivity profile near the characterized water track. The red rectangle defines the fifty-meter approximate range for the position of characterized water track. The n-factor is used to calculate the distance between the receiver and transmitter based on the dipole length.

\section{Conclusion}

From the study, it was discovered that water tracks exist in both permafrost and seasonal-frost (nonpermafrost) areas of the subarctic. However, the types of water tracks in boreal areas and their properties are still not fully identified, and thus require further research. Both of the water tracks characterized in this study provided quite propitious insights into water tracks in the subarctic.

The characterization of the Goldstream Road water track (wider with slight depression) revealed that temperature and saturation are critical parameters in identifying water tracks in boreal regions. More research on intrinsic permeability may result in using it as a third parameter in delineating and groundtruthing water tracks in the future.

The characterization of the water track (relatively narrow track with denser vegetation growth) at Martin's property suggests that the track was formed along the boundary of high-permeability foundation fill and low-permeability natural soil. The mean permeability of the fill is more than 21 times higher than that of the natural soil. This finding reveals that formation of water tracks is not limited to lateral, subsurface constraining layers such as permafrost, but that water tracks can also form along the boundary between two units with relatively different hydraulic properties. 
Attempts made to extract water tracks from remotely sensed images highlight the complexity of mapping water tracks in thickly vegetated subarctic borealis. Handheld thermal IR cameras were able to capture different thermal regime of water tracks, leading to a conclusion that a high-spatial-resolution thermal IR image could be used to automatically extract water tracks in boreal regions. These efforts emphasize the need for future research to gain a better understanding of water tracks in boreal environments. Systematic understanding of water tracks and more mapping experiments will help determine the electromagnetic signatures of different types of water tracks that exist in subarctic borealis.

A low-resistivity signature for water tracks is suggested when the position of a single characterized water track was approximated on the 2012 resistivity survey data. However, more correlations using different techniques are necessary to validate this conclusion.

The conditions at Martin's property demonstrate that water track interceptions can adversely impact engineered infrastructure. The faster rate of damage at the property in the recent years suggests that climate change could be playing a role in the geotechnical implications of water tracks. Furthermore, the appearance of a sinkhole and more subsurface cavities from spring of 2015 are threats not only to the infrastructure but also to human safety.

More investigations are necessary to determine whether the interception of water tracks is contributing to the damage of Goldstream Road. However, the post-winter soil temperature and moisture content measurements suggest that the road fill could be obstructing the flow in the water track despite the presence of a culvert.

\section{$7 \quad$ Recommendations for Future Directions}

First of all, more types of subartic water tracks should be identified and characterized. Based on the attained characteristics and properties of boreal water tracks, accurate mapping techniques should be designed. At the same time, more investigations to develop a better understanding of geotechnical implications of water tracks are recommended as the damage could be intensifying with the changing climate.

All in all, findings from this study underline the unexplored nature of water tracks in science and call for more interest and funding to be invested in investigating water tracks and their interaction with engineered infrastructures.

Acknowledgments. This research was supported in part by a UAF Center for Global Change Student Research Grant with funds from the UAF Office of Undergraduate Research and Scholarly Activity. The authors acknowledge the support in form of geophysical data released by William Schnabel, Jens Munk, and Kevin Bjella.

Our sincere gratitude goes to all of those who helped us in the progress of this research. They include, but are not limited to, Dr. Matt Nolan for aerial imagery, Michael Hatfield from ACUASI, the Geographic Information Network of Alaska (GINA) for SPOT 5 imagery, Jeremy Hale for higherresolution satellite imageries, Martin Harrild for the Thermal IR camera, Aaron Kruse for helping with field work, Rebekah Tsigonis for being a part of the substudy at Martin's Property, and last but not least, Mr. and Mrs. Martin for allowing us to do investigations at their property.

\section{References}

1. J. P. McNamara, D. L. Kane, and L. D. Hinzman, "An analysis of an Arctic channel network using a digital elevation model," Geomorphology, vol. 29, no. 3-4, pp. 339-353, 1999.

2. J. C. Rowland, et al., "Arctic Landscapes in Transition: Responses to Thawing Permafrost", Eos, Transaction, American Geophysical Union, vol. 91, no. 26, pp. 229-230, doi. 10.1029/2010EO260001, 2010.

3. S. J. Levy, G. A. Fountain, N. M. Gooseff, A. K. Welch, and W.B. Lyons, "Water tracks and permafrost in Taylor Valley, Antarctica: Extensive and shallow groundwater connectivity in a cold desert ecosystem," GSA Bulletin, vol. 123, no. 11/12, pp. 2295-2311, 2011. 
4. L. D. Hinzman, et al., "Evidence and implications of recent climate change in northern Alaska and other Arctic regions," Climate Change, vol. 72, no. 3, pp. 251-298, 2005.

5. S. V. Kokelj and M. T. Jorgenson, "Advances in Thermokarst Research," Permafrost and Periglacial Processes

6. E. Trochim, personal communication, 2014.

7. E. W. Schnabel, R. Fortier, M. Kanevskiy, J. Munk, Y. Shur, and E. Trochim, "Geophysical Applications For Arctic/Subarctic Transportation,Planning," Final Report, Alaska University Transportation Center (AUTC), [EXCERPT], 2014. 